\title{
Acceptability and preference drivers of red wines produced from Vitis labrusca and hybrid grapes
}

\author{
Aline Camarão Telles Biasoto a,b,*, Flávia Maria Netto a, \\ Emanuel José Nascimento Marques ${ }^{c}$, Maria Aparecida Azevedo Pereira da Silva ${ }^{a}$ \\ a Department of Food and Nutrition, University of Campinas (UNICAMP), P.O. Box 6121, Campinas, SP, Brazil \\ b Brazilian Agricultural Research Corporation, EMBRAPA Tropical Semi-arid. P.O. Box 23, Petrolina, PE, Brazil \\ ${ }^{c}$ Institute of Chemistry, University of Campinas (UNICAMP). P.O. Box 6154, Campinas, SP, Brazil
}

\section{A R T I C L E I N F O}

\section{Article history:}

Received 15 January 2014

Accepted 29 March 2014

Available online 8 April 2014

\section{Keywords:}

Wine

American grapes

Sensory profile

Consumer test

Physicochemical analyses

\begin{abstract}
A B S T R A C T
Wines produced from non-Vitis vinifera varieties have great economic importance in Brazil and represent more than $80 \%$ of the national production, but scientific information regarding the quality of these wines is rare. The objective of this research was to determine consumer acceptability, the sensory profile and the chemical composition of the most consumed Brazilian red wines produced with Vitis labrusca and promising hybrid varieties, identifying the parameters that drive the preference of consumers. Commercial wines collected directly from different wineries were evaluated regarding their overall acceptance by 120 consumers. Twelve trained panelists developed the sensory profile of the wines using Quantitative Descriptive Analysis (QDA). Physicochemical analyses carried out to determine the $\mathrm{pH}$, titratable and volatile acidity, total solids, alcohol degree, total phenolics, free $\mathrm{SO}_{2}$ and the reducing sugar contents of the wines. The data was analyzed by ANOVA, Tukey test, Internal Preference Mapping (MDPREF), Cluster analysis, Principal Component Analysis (PCA), Partial Least Square regression (PLS), and Extended Internal Preference Map (EPM). In general wines produced from Ives (V. labrusca) grape showed higher aroma/flavor notes described as sweet, grape, grape juice, blackberry and roses. The wines produced from the hybrid grape Máximo differed from those elaborated with the variety Ives, especially due to their higher intensity of earthy/mushroom, vegetative/green beans, woody and yeast sensory notes. The PLS and EPM analyses indicated that fruity notes associated with the aroma and flavor of grape and grape juice were sensory drivers of Brazilian consumers' preference. On the other hand, the majority of the consumers did not like the sensory notes described as earthy/mushroom, vegetative/green beans and yeast found in the wines produced from Máximo. The wine elaborated exclusively with the hybrid Seibel 2 and the wine containing the $V$. labrusca grapes Ives and Isabella were preferred by the majority of the consumers and only a minor segment of consumers appreciated the wines elaborated solely with Máximo grape. Thus the hybrid grape Seibel 2 and the recently developed hybrid Máximo were shown to be promising varieties for the winemaking of quality wines in Brazilian regions where the environmental conditions are not good for the cultivation of $V$. vinifera varieties.
\end{abstract}

(c) 2014 Elsevier Ltd. All rights reserved.

\section{Introduction}

Even though Vitis vinifera is the grape most used for wine making throughout the world, in Brazil, wines elaborated from American grapes (mostly Vitis labrusca) and/or hybrid grapes obtained from crosses between $V$. vinifera and American/hybrid species, have mostly surpassed those made from $V$. vinifera grapes. These wines, known as "table wines", represent more than $80 \%$ of all the wines produced in Brazil, the production being over 210 million liters in 2012 (IBGE. Banco de

\footnotetext{
* Corresponding author at: BR 428, Km 152, P.O. Box 23, Zona Rural, Petrolina, PE, Brazil. 56302-970. Tel.: +55 873866 3723; fax: +55873866 3815 .

E-mail address: aline.biasoto@embrapa.br (A.C.T. Biasoto).
}

dados agregados, 2013). This is probably due to the fact that in several Brazilian regions, the climatic conditions are unfavorable for the growth of $V$. vinifera, since the ripening and harvest of the grapes occurs during the rainy season (Hamada, Ghini, Rossi, Pedro Júnior, \& Fernades, 2008). In addition, the American grapes have the advantage of being more disease resistant, showing good adaptation to adverse weather conditions such as humid summers, amongst others (Amerine \& Singleton, 1984; Jackson, 2008).

The Brazilian government, together with several national research centers such as the Agronomic Institute of Campinas (IAC) and the Brazilian Agricultural Research Agency (EMBRAPA), are developing several hybrid varieties for winemaking. These new varieties are expected to combine the good adaptation, productivity and disease resistance of the American/hybrid grapes, with sensory quality more similar to that 
of the $V$. vinifera varieties (Camargo \& Ritschel, 2008). This is the case of the hybrid variety known as Máximo (IAC 138-22), originating from a cross between Syrah and Seibel 11342, and the variety Sanches (IAC 960-9), generated from Máximo and IAC 577-8; amongst other cultivars.

Several V. labrusca varieties are referred to as "foxy grapes" because they contain methyl anthranilate, a chemical compound that imparts a fruity and/or artificial grape aroma/flavor note to the wine (Jackson, 2009; Reynolds, Lowrey, \& De Savigny, 2005). This was confirmed by Biasoto, Catharino, Sanvido, Eberlin, and Da Silva (2010) who verified that Brazilian wines containing V. labrusca and/or hybrid grapes, notably those made solely with the Ives variety, presented strong flavor notes described as grape and grape juice.

The fruity flavor of table wines is widely demanded by an important sector of Brazilian wine consumers (Castilhos, Silva, \& Bianchi, 2012; Lago-Vanzela et al., 2013), but, as reported by Biasoto et al. (2010), some $V$. labrusca and/or hybrid grapes impart additional flavors to the wine, such as woody, seed and bitterness, and the impact of this on the acceptability by Brazilian consumers is yet unknown.

Due to the great economic importance currently detained by wines from $V$. labrusca and hybrid grapes in Brazil, the objective of this research was to determine the acceptability of both the most consumed red V. labrusca wines, and those obtained from promising hybrid varieties, identifying the sensory and chemical parameters that drive the preference of Brazilian red wines consumers.

\section{Materials and methods}

Wines

The samples consisted of nine red wines produced from $V$. labrusca and/or hybrid grapes: Ives ( $V$. labrusca), Isabella (V. labrusca), Máximo (hybrid grape from Syrah and Seibel 113432), Sanches (hybrid grape from Máximo and IAC 577-8), Seibel 2 (hybrid grape from Alicante Bouschet and Vitis lincecumii); and one wine sample produced from a $V$. vinifera grape known as Barbera. All the wines were from the same harvest and obtained from wineries which voluntarily agreed to take part in this study. All the wineries were located in Sao Paulo State, Brazil and Table 1 specifies the grape species and varieties employed to produce each wine, the annual production of the wineries and the price of a bottle.

In Table 1, the wine referred to as "mixed V. labrusca varieties", is one of the most marketed wines in Brazil, but its composition in terms of grape varieties was maintained in confidentiality by the winery. As shown in Table 1, the above mentioned wine is the least expensive of all the samples tested and one of the cheapest brands in Brazil, but very popular amongst consumers.

\section{Consumer test}

All the samples (Table 1 ) were evaluated by 120 consumers recruited from the State University of Campinas (UNICAMP), Campinas, SP, Brazil. After the Ethics Committee of the State University of Campinas had approved the research project ( protocol nº 393/2007), lecturers, researchers, technicians and graduate students were invited to take part by filling in a recruitment form, and 120 habitual consumers of red wine were selected, 54 women and 66 men, ages ranging from 21 to 35 years old. The selection criterion of the subjects was the consumption of at least one glass of red wine per week during the winter.

The sensory tests were carried out in the Sensory Analysis Laboratory of the Department of Food and Nutrition of the Faculty of Food Engineering of the State University of Campinas (UNICAMP), Campinas, SP, Brazil. Twenty-milliliter $(20 \mathrm{~mL})$ samples of the red wines were evaluated in coded tulip glasses covered with watch glasses. The sample evaluations were carried out at 20 to $22{ }^{\circ} \mathrm{C}$ in individual booths under incandescent white illumination. All the consumers evaluated the overall acceptability of the 10 wine samples using the hybrid hedonic scale proposed by Villanueva and Da Silva (2009), anchored with the terms "disliked extremely" and "liked extremely" at the left and right endpoints, respectively. To avoid tiredness and sensory fatigue amongst the consumers, the ten wine samples were evaluated in two distinct tasting sessions, carried out on two successive days. The effects of the presentation order and first-order carry-over of the samples were controlled using the crossover design proposed by Wakeling and MacFIE (1995). The respondents were also instructed to cleanse their palates with spring water and unsalted crackers before each sample evaluation.

\section{Descriptive analysis}

For the descriptive analysis of the wines, 35 Graduate students from the Food Engineering Faculty, UNICAMP, experienced in the descriptive analysis of food and beverages were invited to take part in the study. The volunteers were initially screened based on their sensitivity to recognize the basic tastes and their discriminative ability to determine differences in the flavor of different red wine samples, as described by Biasoto et al. (2010).

In sequence, they learned and memorized the odors listed in the Wine Aroma Wheel ${ }^{\circledR}$ (Noble et al., 1987) that are usually associated with red wines, such as: floral (linalool), rose, black pepper, cloves, lemon, blackberry, strawberry, peach, apple, grape, grape juice, pineapple, melon, banana, raisin, dried fig, green grass, bell pepper, green beans, tea, almond, honey, buttery (diacetyl), vanilla, oak, mushroom, sulfur dioxide, acetic acid, ethanol, yeast, lactic acid and butyric acid. For this, a sub-set of eight references from the Wine Aroma Wheel ${ }^{\circledR}$ was first presented to each panelist, coded with a random three digit number, and the subjects required to familiarize themselves with

Table 1

Characterization of the red wine samples analyzed in the current study, winery annual production and price per bottle.

\begin{tabular}{|c|c|c|c|c|}
\hline Grape Varieties & Samples & Sample grape composition & $\begin{array}{l}\text { Winery production } \\
\text { (liters per year) }\end{array}$ & $\begin{array}{l}\text { Price per bottle in US\$ } \\
(750 \mathrm{ml} \text { bottle })\end{array}$ \\
\hline \multirow{4}{*}{ V. labrusca } & Ives and Isabella & Ives and Isabella & 10 million & 4.00 \\
\hline & Ives I & $100 \%$ Ives & 4 million & 4.50 \\
\hline & Ives II & $100 \%$ Ives & 6000 & 5.10 \\
\hline & Mixed Vitis labrusca & Unrevealed by the winery & 25 million & 2.90 \\
\hline \multirow[t]{5}{*}{ Hybrids } & Máximo I & 100\% Máximo (IAC 138-22) & 15,000 & 5.80 \\
\hline & Máximo II & 100\% Máximo (IAC 138-22) & 6500 & 6.00 \\
\hline & Ives, Máximo and Sanches & $\begin{array}{l}\text { Ives, Máximo (IAC 138-22) and } \\
\text { Sanches (IAC 960-9) }\end{array}$ & 3500 & 5.00 \\
\hline & Seibel 2 & 100\% Seibel 2 & 12,000 & 4.60 \\
\hline & Seibel 2, Máximo, Ives and Isabella & $\begin{array}{l}\text { Seibel 2, Máximo (IAC 138-22), Ives } \\
\text { and Isabella }\end{array}$ & 118,750 & 4.50 \\
\hline V. vinifera & Barbera & 100\% Barbera & 5000 & 7.00 \\
\hline
\end{tabular}


these odors. Then, they were asked to label each reference, and find the identical standard in a second sub-set containing the same eight odor substances, but coded with different three-digit numbers. The 32 references of the Wine Aroma Wheel ${ }^{\circledR}$ were evaluated in several sessions until 16 of the 35 candidates could correctly label $100 \%$ of the standards offered.

\section{Lexicon and panel training}

The 16 above mentioned panelists compared the ten wines listed in Table 1 during five distinct sessions. Using Kelly's Repertory Grid Method as described in Moskowitz (1983) and in Biasoto et al. (2010), they consensually generated 33 sensory descriptors, as well as their written definitions and references. The panelists also generated a consensual descriptive ballot for the wines, in which the descriptors were associated with a $9 \mathrm{~cm}$ unstructured scale, anchored at the left and right extremes with the terms "none/weak" and "strong", respectively, as proposed by Stone, Sidel, Oliver, Woosley, and Singleton (1974).

In sequence, the descriptive ballot, red wine samples and reference standards were used to train the panel. After the training period, a final selection of the panelists was carried out, where each judge evaluated four red wines with four replications using the descriptive ballot. Twelve individuals showing adequate discriminative power $\left({ }_{\mathrm{p}} \mathrm{F}_{\text {wine }}\right.$ $\leq 0.30$ ), reproducibility $\left({ }_{\mathrm{p}} \mathrm{F}_{\text {replication }} \geq 0.05\right.$ ) and consensus with the rest of the panel for at least $80 \%$ of the descriptors present in the ballot, were selected to take part in the descriptive panel. The panelists, 2 males and 10 females, were aged between 21 and 35 years.

\section{Sensory profile}

The red wine samples $(30 \mathrm{~mL})$ were tested at $20 \pm 2{ }^{\circ} \mathrm{C}$, in clear tulip-shaped glasses, coded with random three-digit numbers and covered with watch glasses. The evaluations were carried out in individual booths under incandescent white illumination. The judges were oriented to rinse their mouths twice with distilled water for $20 \mathrm{~s}$ before tasting the next wine. The panelists smelled the reference standards before starting each evaluation session, in order to refresh their memories.

To control the contrast effect amongst the samples a Cochran and Cox (1957) incomplete balanced block design was used (design plan 11.6), where four wines were tested in each session. Overall, each judge evaluated each of the ten red wines (Table 1) with six repetitions, in a total of 15 sessions. For each repetition, a different wine bottle was opened.

\section{Chemical analysis}

Following procedures detailed in AOAC - Association of official analytical chemists (2005), the $\mathrm{pH}$ of each sample was measured using a pH meter (Ion Analyzer EA 940, Orion Expandable, Boston, USA). The ethanol content $(\%, v / v)$ was determined at $20{ }^{\circ} \mathrm{C}$ using a pycnometer. The total solids content was measured by evaporating a $20 \mathrm{~mL}$ sample to dryness at $100{ }^{\circ} \mathrm{C}$ to constant weight. In order to determine the volatile acidity (VA) (acetic acid in $\mathrm{g} \cdot \mathrm{L}^{-1}$ ) of the wines, one $10 \mathrm{~mL}$ aliquot was first steam distilled and the distillates titrated with $0.1 \mathrm{~N} \mathrm{NaOH}$ using phenolphthalein as the indicator. The titratable acidity (TA) (tartaric acid in $\mathrm{g} \cdot \mathrm{L}^{-1}$ ) was measured by adding $10 \mathrm{ml}$ of wine to $125 \mathrm{~mL}$ of deionized water and titrating with $0.1 \mathrm{~N} \mathrm{NaOH}$ to an endpoint of $\mathrm{pH}$ 8.2. The reducing sugars content of the wines $\left(\mathrm{g} \cdot \mathrm{L}^{-1}\right)$ was determined by the Lane-Eynon method. For this analysis, an aliquot of $250 \mathrm{~mL}$ of clarified wine was used to titrate a $60 \mathrm{~mL}$ mixture of Fehling A $(10 \mathrm{~mL})$ and $B(10 \mathrm{~mL})$ solutions in water. Methylene blue was used to determine the endpoint. The total phenolic content (gallic acid in $\mathrm{g} \cdot \mathrm{L}^{-1}$ ) was measured using a spectrophotometric method (model Du-70, Mark Beckman Instruments Inc., Fullerton, C.A., USA) and the Folin-Ciocalteau reagent (Rossi \& Singleton, 1965). Free sulfur dioxide $\left(\mathrm{mg} \cdot \mathrm{L}^{-1}\right)$ was determined by iodometry according to the Ripper method, using starch as the endpoint indicator. For the analysis, an aliquot of wine $(1 \mathrm{~mL})$ acidified with $\mathrm{HCl}$ was titrated with a standardized $0.02 \mathrm{~N}$ solution of $\mathrm{I}_{2}$ (Ough \& Amerine, 1988). All analyses were carried out using two different bottles of each wine, and for each bottle, the data were collected in triplicate.

\section{Data analysis}

The consumer acceptance data was analyzed by ANOVA, Tukey's multiple means comparison test $(\mathrm{p} \leq 0.05)$ and Internal Preference Mapping - MDPREF (MacFIE \& Thomson, 1988) and the Hierarchical Clustering Analysis, the latter being carried out on the nonstandardized data using Ward's minimum variance method. The consumers were segmented by MDPREF and the cluster analysis in order to identify groups of consumers with different preference patterns. The data from the sensory descriptive and physicochemical analyses were evaluated using ANOVA, Tukey test and the Principal Component Analysis - PCA. These statistical analyses were carried out using version 9.3 of SAS (SAS ${ }^{\circledR}$ Institute Inc., Cary, N.C., 2011). The overall consumer acceptance was also correlated with the sensory descriptive data by way of the Partial Least Squares - PLS regression at a 5\% level of significance, using the XLStat software (Addinsoft Inc., Anglesey, UK, 2013). To relate the data from the descriptive analysis and physicochemical analyses to the consumer test result, an Extended Internal Preference Mapping - EPM was generated using the XLStat software (Addinsoft Inc., Anglesey, UK, 2013). Finally, the Pearson correlation analyses were applied to the consumer, descriptive and physicochemical data $(\mathrm{p} \leq 0.05)$.

\section{Results and discussion}

\section{Consumer acceptability}

The Fig. 1 presents the Internal Preference Map - MDPREF generated by the individual responses of the 120 consumers who evaluated the 10 wine samples. Two significant dimensions ( $\mathrm{p} \leq 0.05$ ) were obtained, which together explained approximately $40 \%$ of the data variability.

In Fig. $1 \mathrm{~A}$ each wine is represented by an ellipse, which delimits the $95 \%$ confidence interval associated with its acceptance. The 120 consumers who evaluated the samples can be found in Fig. 1B, represented by the numbers 1 to 120 , and each consumer is close to the samples of his/her preference (MacFIE \& Thomson, 1988). The consumers allocated out of the $95 \%$ confidence region delimited by the central eclipse in Fig. $1 \mathrm{~B}$, were those who showed significant correlations $(\mathrm{p} \leq 0.05)$ of their hedonic values with the first two preference dimensions (dimensions significant at $\mathrm{p} \leq 0.05$ ). One can consider that these consumers, 52 individuals in all, were those who segmented the samples more clearly as a function of preference in their judgments (Villanueva \& Da Silva, 2009).

To interpret the results of the MDPREF, one should superimpose Fig. 1A on Fig. 1B, where it can be seen that the majority of the 52 significant consumers ( $\mathrm{p} \leq 0.05$ ) were located close to the hybrid grape wine Seibel 2, indicating that this sample was much more preferred by the consumers. However, of the 52 significant consumers, 28 were found located in the upper right hand quadrant of Fig. $1 \mathrm{~B}$ and 19 in the lower right hand quadrant. This indicates that although the majority of the 52 significant consumers $(\mathrm{p} \leq 0.05)$ showed greater preference for Seibel 2, one segment of this group also showed preference for the Ives and Isabella wine and for the wine elaborated with the mixture of the grapes Seibel 2, Maximo, Ives and Isabella (segment 1), whereas the other part preferred the wine Máximo II (segment 2). Fig. 1 also suggests that the wine Barbera, the only one elaborated with $V$. vinifera grapes, was preferred by an insignificant number of consumers.

The above results were mostly confirmed in Table 2, where it can be seen that, in general, the 120 consumers showed greater acceptance of the wine Seibel 2 and of the Ives and Isabella wine, and less acceptance of the Barbera and Máximo I wines ( $\mathrm{p} \leq 0.05)$. These results also coincided with those determined by the MDPREF for the significantly fitted 

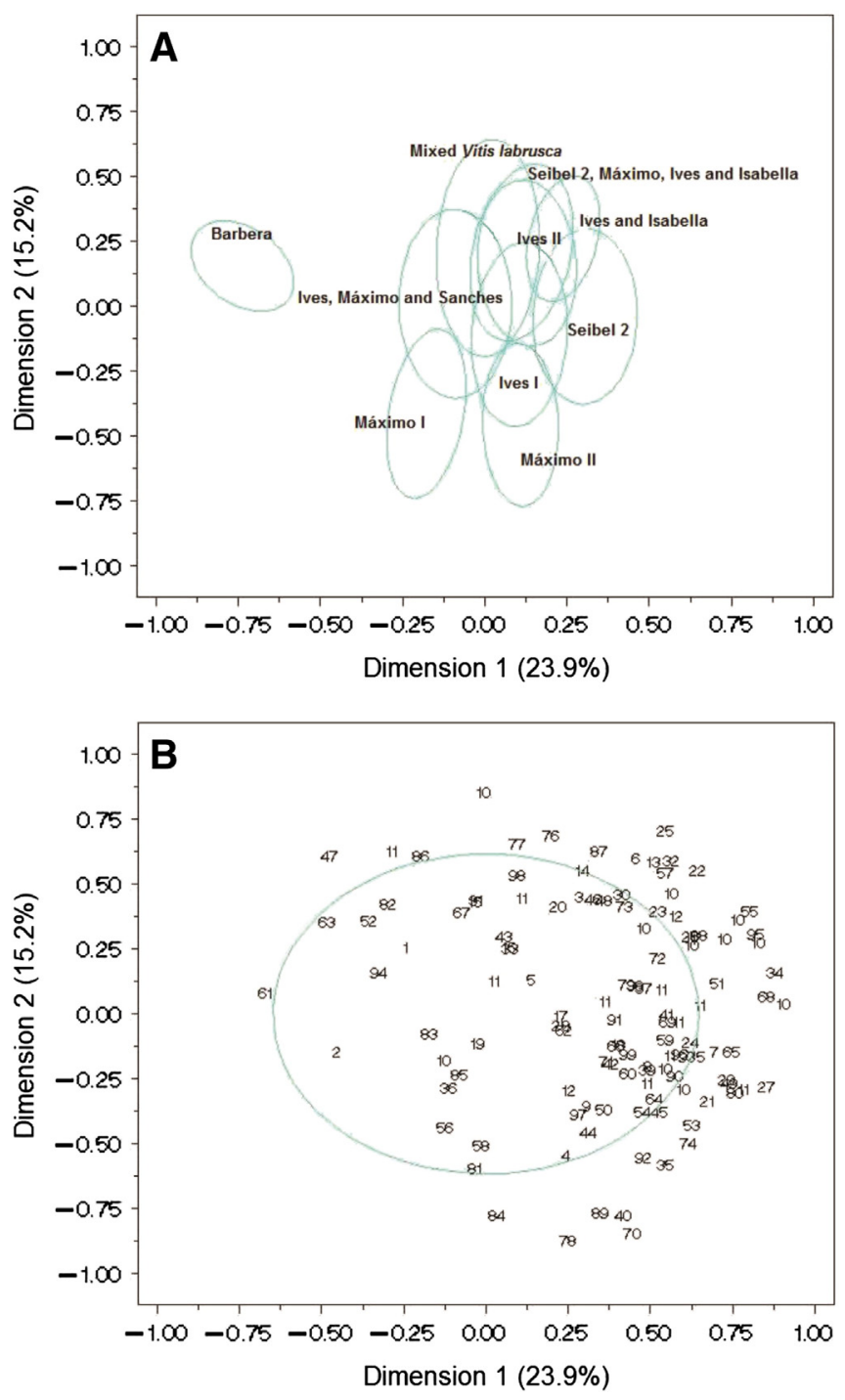

Fig. 1. (A) Internal Preference Mapping (MDPREF) of the overall acceptance data generated by the hybrid hedonic scale, showing the configuration of the wine samples $(n=10)$; (B) MDPREF of the overall acceptance data generated by the hybrid hedonic scale showing the configuration of the consumers $(n=120)$.

consumers ( $\mathrm{p} \leq 0.05)$ ( $n=52$ consumers) and those of segment 1 ( $n=$ 28 consumers). However, on analyzing the consumer preferences in segment 2, located in the lower right hand quadrant of Fig. 2B ( $n=$
19 consumers), it can be seen that in addition to showing preference for the Seibel 2 wine and rejection of the $V$. vinifera Barbera wine, these individuals also showed preference for the Maximo I and II wines, both rejected by the consumers of segment 1 (Table 2 ).

Thus in general it can be said that there was a consensus amongst the consumers in the sense that they preferred the wine Seibel 2 and disliked the $V$. vinifera Barbera wine, the most expensive one amongst those evaluated (Table 1). However, with regards the wines elaborated with the hybrid grapes Maximo I and II, the consumers segmented themselves between those who preferred them (segment 2) and those who rejected them (segment 2), these also being amongst the more highly priced wines as compared to the others.

It is important to mention that the hedonic means obtained for the wines in the current study (Table 2) are within the same range found by Villanueva and Da Silva (2009), where the authors assessed the acceptance of 10 commercial $V$. vinifera wines amongst consumers drawn from the same population through a hybrid hedonic scale. As in Villanueva and Da Silva (2009), in the current study, the consumers generally preferred the lower priced wines.

The cluster analysis segmented the consumers into five distinct clusters containing, respectively, 29, 45, 15, 16 and 15 individuals each. Table 3 presents the means obtained for the overall acceptability of each wine as awarded by each cluster, as well as the correlation between the data generated by consumers located in each cluster and those placed in segments 1 and 2 of the MDPREF (Table 2).

Although the cluster analysis allowed for greater segmentation of the consumers as compared to the MDPREF analysis, the positive correlations between the results of the consumers located in segment 1 of the MDPREF (Table 2$)$, and those placed in cluster $1(p=0.01)$, cluster $2(\mathrm{p}=0.02)$, cluster $4(\mathrm{p}=0.02)$ and cluster $5(\mathrm{p}=0.04)$, indicated a similar preference pattern amongst them (Table 3$)$.

Like the 28 consumers located in segment 1 of the MDPREF, the consumers in clusters 1, 2 and 4 showed a greater preference for the wines produced with the grapes Seibel 2 and Ives and Isabella, and Ives (Ives I or Ives II), and less preference for the wine elaborated with the $V$. vinifera Barbera grape (Table 3). The consumers in cluster 5 showed a slightly different preference pattern, but still the wines produced with the mixture of Isabella and Ives, and Ives I and II grapes were amongst their favorites, and the wine produced with the $V$. vinifera Barbera grape the least preferred (Table 3 ).

Table 3 shows that although the consumers located in clusters 1,2 and 4 showed similarity regarding their preference patterns, they exhibited different liking patterns and used different portions of the hedonic scale to rate the wines. Thus, while the acceptance means of the consumers in cluster 1 ranged from 5 (neither liked/nor disliked) to 8 (liked very much) indicating that in general they liked the wines, the acceptance means of the consumers in cluster 4 ranged from 1 (disliked extremely) to 4 (disliked slightly), indicating that, overall,

Table 2

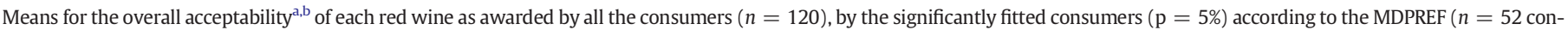

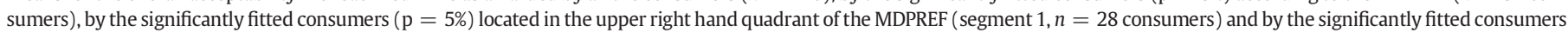
( $\mathrm{p}=5 \%$ ) located in the lower right hand quadrant of the MDPREF (segment 2, $n=19$ consumers).

\begin{tabular}{|c|c|c|c|c|c|}
\hline Grape Varieties & Samples & $\begin{array}{l}\text { All the consumers } \\
(n=120 \text { consumers })\end{array}$ & $\begin{array}{l}\text { Significant Consumers } \\
(n=52 \text { consumers })\end{array}$ & $\begin{array}{l}\text { Segment } 1 \\
(n=28 \text { consumers })\end{array}$ & $\begin{array}{l}\text { Segment } 2 \\
(n=19 \text { consumers })\end{array}$ \\
\hline \multirow[t]{4}{*}{ Vitis labrusca } & Ives and Isabella & $5.7 \mathrm{a}$ & $6.2 \mathrm{ab}$ & $6.7 \mathrm{a}$ & $5.2 \mathrm{bc}$ \\
\hline & Ives I & $5.5 \mathrm{ab}$ & $5.9 \mathrm{abc}$ & $5.6 \mathrm{bc}$ & $6.2 \mathrm{ab}$ \\
\hline & Ives II & $5.5 \mathrm{ab}$ & $5.6 \mathrm{abc}$ & $5.9 \mathrm{abc}$ & $5.1 \mathrm{bc}$ \\
\hline & Mixed V. labrusca & $5.3 \mathrm{abc}$ & $5.5 \mathrm{abc}$ & $5.6 \mathrm{abc}$ & $4.9 \mathrm{c}$ \\
\hline \multirow[t]{5}{*}{ Hybrids } & Máximo I & $4.8 \mathrm{c}$ & $4.5 \mathrm{~d}$ & $3.2 \mathrm{e}$ & $6.3 \mathrm{ab}$ \\
\hline & Máximo II & $5.2 \mathrm{abc}$ & $5.0 \mathrm{~cd}$ & $4.2 \mathrm{de}$ & $6.7 \mathrm{a}$ \\
\hline & Ives, Máximo and Sanches & $5.0 \mathrm{bc}$ & $5.2 \mathrm{bcd}$ & $4.8 \mathrm{~cd}$ & $5.6 \mathrm{abc}$ \\
\hline & Seibel 2 & $5.8 \mathrm{a}$ & $6.4 \mathrm{a}$ & $6.3 \mathrm{ab}$ & $6.7 \mathrm{a}$ \\
\hline & Seibel 2, Máximo, Ives and Isabella & $5.4 \mathrm{abc}$ & $5.8 \mathrm{abc}$ & $6.2 \mathrm{ab}$ & $5.2 \mathrm{bc}$ \\
\hline Vitis vinifera & Barbera & $3.6 \mathrm{~d}$ & $3.3 \mathrm{e}$ & $3.0 \mathrm{e}$ & $2.8 \mathrm{~d}$ \\
\hline
\end{tabular}

$1=$ disliked extremely; 9 = liked extremely.

${ }^{\mathrm{b}}$ In the same column, means with letters in common are not significantly different ( $\left.\mathrm{p} \leq 0.05\right)$ according to Tukey's test. 


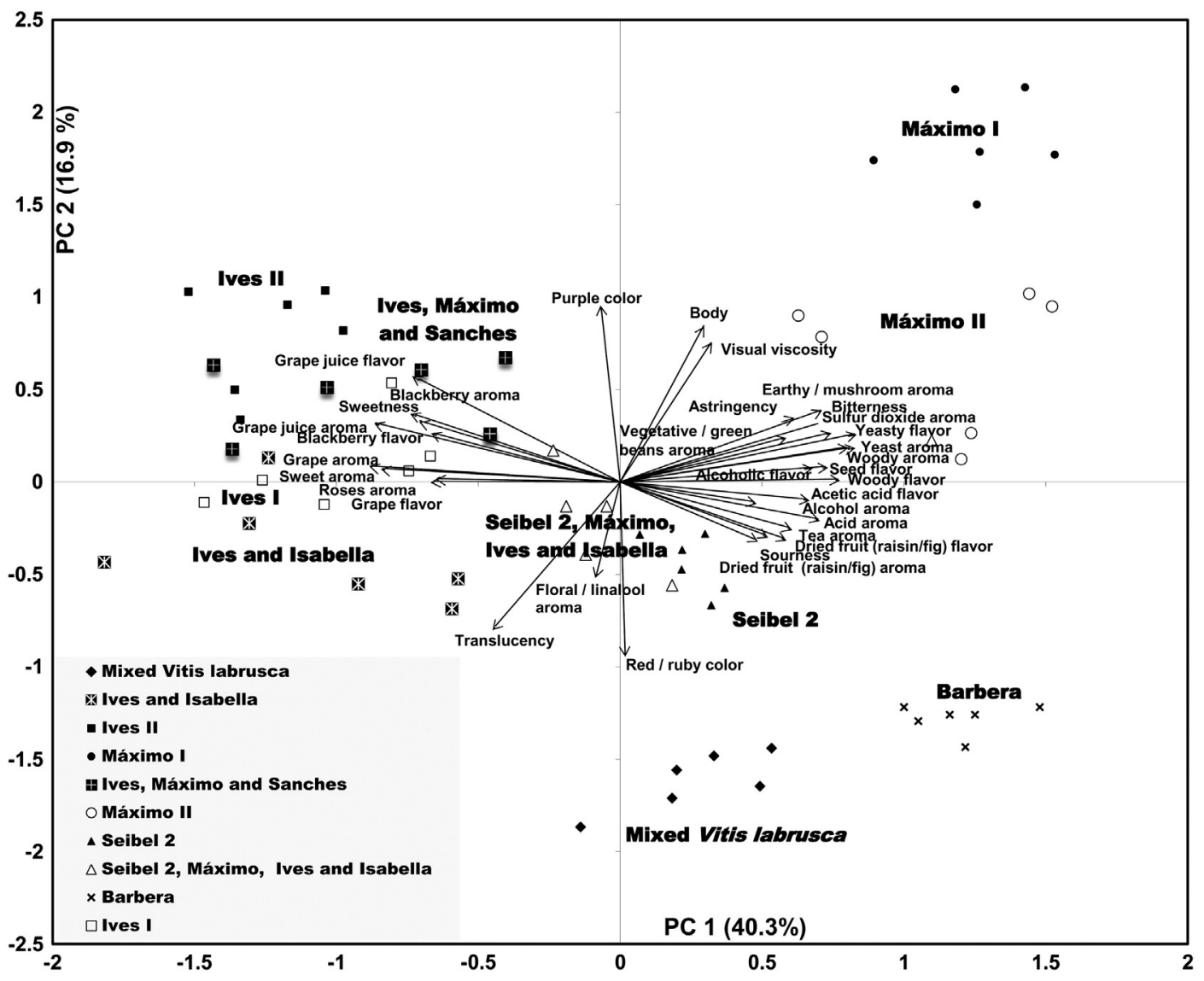

Fig. 2. PCA generated with the sensory data of all the 33 descriptors developed by the trained sensory panel $\left(n_{1}=12\right.$ judges, $n_{2}=6$ repetitions/sample).

they disliked the samples. This information is very important and was lost in the segmentation of the consumers by the MDPREF analysis (Table 2).

Table 3 also shows a positive correlation ( $p=0.01$ ) between the results of the consumers located in cluster 3 and those located in segment 2 of the MDPREF (Table 2), suggesting that they have a similar preference pattern. For these consumers, the wine elaborated with Seibel 2 and that made with the Ives and Isabella varieties were amongst the most preferred; but unlike the consumers from the MDPREF segment 1 and those located in clusters 1, 2, 4 and 5, they did not reject the wines produced with the hybrid grapes Maximo (Maximo I and Maximo II). These subjects also disliked the $V$. vinifera Barbera wine.

\section{Sensory profile}

Significant differences ( $\mathrm{p} \leq 0.05$ ) were found amongst the ten wines listed in Table 1 for all the 33 descriptors generated by the trained panel (Table 4). No significant wine *judge interaction $(\mathrm{p} \leq 0.05)$ was detected, proving that the training of the descriptive panel was adequate. Overall, the results of the Principal Component Analysis (PCA) shown

Table 3

Means for the overall acceptability ${ }^{\mathrm{a}, \mathrm{b}}$ of each red wine as awarded by the consumers located in the five clusters generated by the hierarchical cluster analysis.

\begin{tabular}{|c|c|c|c|c|c|c|}
\hline Grape varieties & Samples & $\begin{array}{l}\text { Cluster } 1 \\
(n=29 \text { consumers) }\end{array}$ & $\begin{array}{l}\text { Cluster } 2 \\
(n=45 \text { consumers })\end{array}$ & $\begin{array}{l}\text { Cluster } 3 \\
(n=15 \text { consumers })\end{array}$ & $\begin{array}{l}\text { Cluster } 4 \\
(n=16 \text { consumers })\end{array}$ & $\begin{array}{l}\text { Cluster } 5 \\
(n=15 \text { consumers })\end{array}$ \\
\hline \multirow[t]{4}{*}{ Vitis labrusca } & Ives and Isabella & $7.30 \mathrm{a}$ & $5.7 \mathrm{abc}$ & $4.74 \mathrm{bcd}$ & $3.48 \mathrm{abc}$ & $6.14 \mathrm{ab}$ \\
\hline & Ives I & $6.77 \mathrm{ab}$ & $5.22 \mathrm{bc}$ & $6.10 \mathrm{ab}$ & $2.18 \mathrm{bc}$ & $6.74 \mathrm{a}$ \\
\hline & Ives II & $7.00 \mathrm{a}$ & $5.04 \mathrm{bc}$ & $6.25 \mathrm{ab}$ & $3.05 \mathrm{abc}$ & $5.73 \mathrm{abc}$ \\
\hline & Mixed V. labrusca & $6.25 \mathrm{abc}$ & $6.34 \mathrm{a}$ & 3.83 de & $3.20 \mathrm{abc}$ & $3.79 \mathrm{~cd}$ \\
\hline \multirow[t]{5}{*}{ Hybrids } & Máximo I & $5.83 \mathrm{bc}$ & $4.89 \mathrm{bcd}$ & $5.89 \mathrm{ab}$ & $2.46 \mathrm{bc}$ & $3.82 \mathrm{~cd}$ \\
\hline & Máximo II & $6.64 \mathrm{ab}$ & $4.73 \mathrm{~cd}$ & $5.60 \mathrm{abc}$ & $3.15 \mathrm{abc}$ & $5.25 \mathrm{abc}$ \\
\hline & Ives, Máximo and Sanches & $6.31 \mathrm{abc}$ & $4.83 \mathrm{~cd}$ & $6.32 \mathrm{a}$ & $2.61 \mathrm{abc}$ & $4.07 \mathrm{bc}$ \\
\hline & Seibel 2 & $7.23 \mathrm{a}$ & $5.91 \mathrm{ab}$ & $6.40 \mathrm{a}$ & $4.08 \mathrm{a}$ & $3.87 \mathrm{~cd}$ \\
\hline & Seibel 2, Máximo, Ives and Isabella & $6.69 \mathrm{ab}$ & $5.07 \mathrm{bc}$ & $4.32 \mathrm{~cd}$ & $3.64 \mathrm{ab}$ & $6.75 \mathrm{a}$ \\
\hline Vitis vinifera & Barbera & $5.51 \mathrm{c}$ & $3.94 \mathrm{~d}$ & $2.69 \mathrm{e}$ & $1.90 \mathrm{c}$ & $1.65 \mathrm{~d}$ \\
\hline \multirow{2}{*}{\multicolumn{2}{|c|}{ Correlation with Segment 1 of the MDPREF ${ }^{c}$}} & $r=0.82$ & $r=0.72$ & $r=0.23$ & $r=0.73$ & $r=0.66$ \\
\hline & & $\mathrm{p}=0.01$ & $\mathrm{p}=0.02$ & $\mathrm{p}=0.53$ & $\mathrm{p}=0.02$ & $\mathrm{p}=0.04$ \\
\hline \multirow{2}{*}{\multicolumn{2}{|c|}{ Correlation with Segment 2 of the MDPREF ${ }^{d}$}} & $r=-0.02$ & $r=0.41$ & $r=0.82$ & $r=0.43$ & $r=0.49$ \\
\hline & & $\mathrm{p}=0.95$ & $\mathrm{p}=0.24$ & $\mathrm{p}=0.01$ & $\mathrm{p}=0.21$ & $\mathrm{p}=0.15$ \\
\hline
\end{tabular}

a 1 = disliked extremely; 9 = liked extremely.

b In the same column, means with letters in common are not significantly different ( $\mathrm{p} \leq 0.05)$ according to Tukey's test.

c Pearson coefficients from the correlation between the acceptance means of each cluster for each sample, and the correspondent data from segment 1 of the MDPREF (Table 2).

d Pearson coefficients from the correlation between the acceptance means of each cluster for each sample, and the correspondent data from segment 2 of the MDPREF (Table 2). 
Table 4

Mean sensory scores ${ }^{\mathrm{a}}$ for appearance and aroma descriptors as rated by the trained sensory panel for each red wine $\left(n_{1}=12\right.$ judges, $n_{2}=6$ repetitions/sample).

\begin{tabular}{|c|c|c|c|c|c|c|c|c|c|c|}
\hline \multicolumn{11}{|c|}{ Wines and respective grape varieties } \\
\hline \multirow[t]{2}{*}{ Descriptors } & \multicolumn{4}{|l|}{ V. labrusca } & \multicolumn{5}{|l|}{ Hybrids } & \multirow{2}{*}{$\frac{\text { V. vinifera }}{\text { Barbera }}$} \\
\hline & Ives and Isabella & Ives I & Ives II & Mixed V. labrusca & Máximo I & Máximo II & Ives, Máximo and Sanches & Seibel 2 & $\begin{array}{l}\text { Seibel 2, Máximo, } \\
\text { Ives and Isabella }\end{array}$ & \\
\hline \multicolumn{11}{|l|}{ Appearance } \\
\hline Purple color & $3.5 \mathrm{~d}$ & $6.9 \mathrm{~b}$ & $4.8 \mathrm{c}$ & $1.7 \mathrm{e}$ & $8.1 \mathrm{a}$ & $5.5 c$ & $5.4 \mathrm{c}$ & $4.9 \mathrm{c}$ & $4.7 \mathrm{c}$ & $1.7 \mathrm{e}$ \\
\hline Red/ruby color & $4.9 \mathrm{bc}$ & $2.0 \mathrm{f}$ & 4.0de & 5.7ab & $0.8 \mathrm{~g}$ & $3.3 e$ & 3.4de & $4.1 \mathrm{~cd}$ & $4.1 \mathrm{~cd}$ & $6.1 \mathrm{a}$ \\
\hline Translucency & $4.7 \mathrm{ab}$ & $3.2 \mathrm{~d}$ & $4.5 \mathrm{abc}$ & $5.0 \mathrm{a}$ & $1.0 \mathrm{f}$ & $2.1 \mathrm{e}$ & $3.9 \mathrm{bcd}$ & $3.7 \mathrm{~cd}$ & $3.7 \mathrm{~cd}$ & $4.5 \mathrm{abc}$ \\
\hline Visual viscosity & $1.7 \mathrm{~cd}$ & $2.2 \mathrm{bc}$ & $2.4 \mathrm{bc}$ & $1.2 \mathrm{~d}$ & $3.8 \mathrm{a}$ & $2.5 \mathrm{~b}$ & $1.9 \mathrm{bcd}$ & $1.8 \mathrm{bcd}$ & $2.3 \mathrm{bc}$ & $2.0 \mathrm{bc}$ \\
\hline \multicolumn{11}{|l|}{ Aroma } \\
\hline Grape juice & $5.6 a b$ & $5.7 a$ & $5.6 \mathrm{ab}$ & 3.8de & $4.1 d$ & $4.1 \mathrm{~d}$ & $5.6 a b$ & $4.4 \mathrm{~cd}$ & $4.9 \mathrm{bc}$ & $3.4 \mathrm{e}$ \\
\hline Grape & $4.2 \mathrm{a}$ & $4.0 \mathrm{a}$ & 3.9ab & $3.2 \mathrm{bc}$ & $2.9 \mathrm{~cd}$ & $2.6 \mathrm{~cd}$ & $3.9 \mathrm{ab}$ & $3.1 \mathrm{~cd}$ & $3.3 \mathrm{bc}$ & $2.5 \mathrm{~d}$ \\
\hline Sweet & $5.2 \mathrm{a}$ & $5.4 \mathrm{a}$ & $5.2 \mathrm{a}$ & $3.8 \mathrm{~b}$ & $3.7 \mathrm{~b}$ & $3.7 \mathrm{~b}$ & $5.6 \mathrm{a}$ & $4.0 \mathrm{~b}$ & $4.4 \mathrm{~b}$ & $4.2 \mathrm{~b}$ \\
\hline Acid & $2.9 \mathrm{c}$ & $3.1 \mathrm{bc}$ & $3.1 \mathrm{bc}$ & $3.8 \mathrm{ab}$ & 3.7ab & $3.8 \mathrm{ab}$ & $3.2 \mathrm{bc}$ & $4.0 \mathrm{a}$ & 3.7ab & $4.1 \mathrm{a}$ \\
\hline Alcohol & $4.8 \mathrm{~b}$ & $4.8 \mathrm{~b}$ & $5.3 \mathrm{~b}$ & $5.4 \mathrm{ab}$ & $5.4 \mathrm{ab}$ & $5.4 \mathrm{ab}$ & $4.8 \mathrm{~b}$ & $6.0 \mathrm{a}$ & $6.0 \mathrm{a}$ & $5.2 \mathrm{~b}$ \\
\hline Dried fruit (raisin/fig) & $2.33 b$ & $2.24 b$ & $2.71 \mathrm{~b}$ & $2.78 \mathrm{ab}$ & $2.71 \mathrm{~b}$ & $2.64 b$ & $2.41 \mathrm{~b}$ & $2.55 b$ & $2.69 \mathrm{~b}$ & $3.38 \mathrm{a}$ \\
\hline Blackberry & $3.8 \mathrm{abc}$ & $4.2 \mathrm{ab}$ & $4.4 \mathrm{a}$ & $2.5 \mathrm{f}$ & 3.1def & 3.1def & $4.2 \mathrm{ab}$ & 3.3cde & $3.5 \mathrm{bcd}$ & 2.7ef \\
\hline Sulfur dioxide & $2.08 \mathrm{~b}$ & $2.27 \mathrm{~b}$ & $2.40 \mathrm{~b}$ & $2.46 \mathrm{~b}$ & $3.53 \mathrm{a}$ & $3.56 a$ & $2.14 b$ & $2.38 \mathrm{~b}$ & $2.11 \mathrm{~b}$ & $3.33 a$ \\
\hline Floral/linalool & $2.3 \mathrm{ab}$ & $2.6 a b$ & $2.6 a b$ & $2.7 \mathrm{a}$ & $2.0 \mathrm{~b}$ & $2.4 \mathrm{ab}$ & $2.3 \mathrm{ab}$ & $2.6 a b$ & $2.5 \mathrm{ab}$ & $2.6 a b$ \\
\hline Rose & $1.87 \mathrm{ab}$ & $2.10 \mathrm{a}$ & $1.97 a b$ & $1.36 \mathrm{bc}$ & $1.37 \mathrm{bc}$ & $1.11 \mathrm{c}$ & $2.12 \mathrm{a}$ & $1.48 \mathrm{bc}$ & $1.63 \mathrm{abc}$ & $1.68 \mathrm{abc}$ \\
\hline Tea & $0.8 \mathrm{ab}$ & $0.7 \mathrm{~b}$ & $0.7 \mathrm{~b}$ & $1.2 \mathrm{a}$ & $1.0 \mathrm{ab}$ & $1.3 \mathrm{a}$ & $0.9 \mathrm{ab}$ & $1.1 \mathrm{ab}$ & $1.1 \mathrm{ab}$ & $1.2 \mathrm{a}$ \\
\hline Earthy/mushroom & $1.0 \mathrm{bc}$ & $1.1 \mathrm{bc}$ & $1.1 \mathrm{bc}$ & $1.0 \mathrm{bc}$ & $2.7 \mathrm{a}$ & $2.6 a$ & $1.6 \mathrm{~b}$ & $0.9 c$ & $1.1 \mathrm{bc}$ & $2.3 \mathrm{a}$ \\
\hline Vegetative/green beans & 1.0de & $0.9 \mathrm{e}$ & 1.0de & $1.2 \mathrm{cde}$ & $1.9 a$ & $1.6 \mathrm{abc}$ & $1.4 \mathrm{bcd}$ & $0.8 \mathrm{e}$ & $0.9 \mathrm{e}$ & $1.7 \mathrm{ab}$ \\
\hline Woody & $2.1 \mathrm{c}$ & $2.4 \mathrm{c}$ & $2.3 c$ & $2.6 c$ & $3.1 \mathrm{ab}$ & $3.2 \mathrm{a}$ & $2.4 \mathrm{c}$ & $2.6 b c$ & $2.6 b c$ & $3.1 \mathrm{ab}$ \\
\hline Yeast & $1.6 \mathrm{~b}$ & $1.5 \mathrm{~b}$ & $1.8 \mathrm{~b}$ & $1.9 b$ & $2.7 \mathrm{a}$ & $2.5 \mathrm{a}$ & $1.7 \mathrm{~b}$ & $1.5 \mathrm{~b}$ & $1.8 \mathrm{~b}$ & $2.7 \mathrm{a}$ \\
\hline
\end{tabular}

${ }^{a}$ Means in the same line showing common letters are not significantly different ( $\mathrm{p} \leq 0.05$ ) according to Tukey's test.

in Fig. 2 suggested that the aroma descriptors discriminated the wines better than their correspondent flavor descriptor, and also that these two classes of descriptors correlated with each other. Table 4 shows the mean values obtained for the appearance and aroma descriptors of the wines evaluated, but not their flavor notes, which were previously explored in an earlier study reported by Biasoto et al. (2010).

In Fig. 2 all five wines elaborated with Ives grapes ( $V$. labrusca) are located on the left hand side of the figure, indicating similarity amongst their sensory profiles despite the fact they came from different wineries. The PCA suggests that these wines differed from those located on the right hand side of the Fig. 2, due to the higher intensity of aroma and flavor notes described as sweet, grape, grape juice, blackberry and roses. The greatest difference occurred between samples located on the far left of Fig. 2, namely the two 100\% Ives wines (Ives I and Ives II), the Ives and Isabella wine and the wine elaborated with the grapes Ives, Máximo and Sanches and the samples located on the far right of Fig. 2, namely the Máximo (Máximo I and Máximo II) and Barbera wines. Table 4 confirms that these two group of wines differed significantly ( $\mathrm{p} \leq 0.05$ ) for the aroma notes described as "sweet", "grape" and "grape juice", in agreement with several authors who reported that V. labrusca varieties such as Ives, Concord, Isabella and Niagara, amongst others, contained methyl anthranilate, a phenol-derived ester that imparts fruity and/or artificial grape aroma/flavor notes to the wine (Jackson, 2009; Reynolds et al., 2005).

The two wines elaborated solely with the hybrid grape Máximo (Máximo I and Máximo II) are located close together on the right hand side of Fig. 2, indicating they had similar sensory profiles even though they came from different wineries. The PCA suggests that these wines differed from those elaborated with the Ives grapes, especially from those located on the far left side of Fig. 2, due to their higher intensity of earthy/mushroom, vegetative/green beans, woody, yeast and sulfur dioxide aroma and/or flavor notes. Table 4 confirms that the Máximo wines differed significantly ( $p \leq 0.05$ ) from the two $100 \%$ Ives wines (Ives I and Ives II), the Ives and Isabella wine and the wine elaborated with Ives, Máximo and Sanches regarding the aroma notes described as earthy/mushroom, woody, sulfur dioxide and yeast. They differed from all the other wines but not from the Barbera wine with respect to the earthy/mushroom, sulfur dioxide and yeast aromas $(\mathrm{p} \leq 0.05)$. The Máximo I wine also presented the most intense purple color, as confirmed by the $\mathrm{p} \leq 0.05$ in Table 4 .

The location of the wine Barbera (V. vinifera) on the right hand side of Fig. 2 and the results presented in Table 4 indicate that this wine did not differ $(\mathrm{p} \leq 0.05)$ from the Máximo wines regarding any aroma descriptor, except grape juice and dried fruit.

The wine elaborated with the hybrid grape Seibel 2 is located in the center of Fig. 2, close to the wine elaborated with the grapes Seibel 2, Isabella, Máximo and Ives. These two wines showed intermediate aroma and flavor intensities across most of the 33 descriptors evaluated.

\section{Sensory preference drivers}

Fig. 3A shows the results obtained in the Partial Least Squares (PLS) analysis generated using the values for overall acceptance awarded by the 120 consumers who took part in the test (dependent variable), and the mean intensities of the 33 descriptors analyzed by the descriptive panel (independent variables). Fig. 3B shows the PLS generated with the results of the significantly fitted MDPREF consumers ( $p \leq 0.05)$ ( $n=52$ consumers), Fig. 3C shows the PLS for the significantly fitted MDPREF consumers of segment 1 ( $n=28$ consumers) and Fig. 3D shows the PLS for the significantly fitted MDPREF consumers of segment 2 ( $n=19$ consumers). In turn, Fig. 4A, B, C, D and E shows the PLS regressions obtained using the overall acceptance values of the consumers located, respectively, in cluster 1 ( $n=29$ consumers), cluster 2 ( $n=45$ consumers), cluster 3 ( $n=15$ consumers), cluster 4 ( $n=16$ consumers) and cluster 5 ( $n=15$ consumers); previously characterized in Table 3.

In Figs. 3 and 4, the descriptors placed in the upper part, whose confidence interval did not include the value zero for the regression coefficient, represent sensory notes that contributed significantly ( $\mathrm{p} \leq 0.05$ ) to increasing acceptance amongst the consumers (Cadena et al., 2013; Tenenhaus, Pagès, Ambroisine, \& Guinot, 2005). This was the case for the notes of alcohol aroma and flavor and grape flavor in the PLS of the 120 consumers (Fig. 3A), for the note of grape aroma in the PLS of both the 52 consumers significantly $(\mathrm{p} \leq 0.05)$ fitted in MDPREF (Fig. 2B) and those of segment 1 (Fig. 3C); and grape juice flavor and sweetness in the PLS of the 19 significantly fitted $(\mathrm{p} \leq 0.05)$ MDPREF 

(Int. of conf. 95\%)

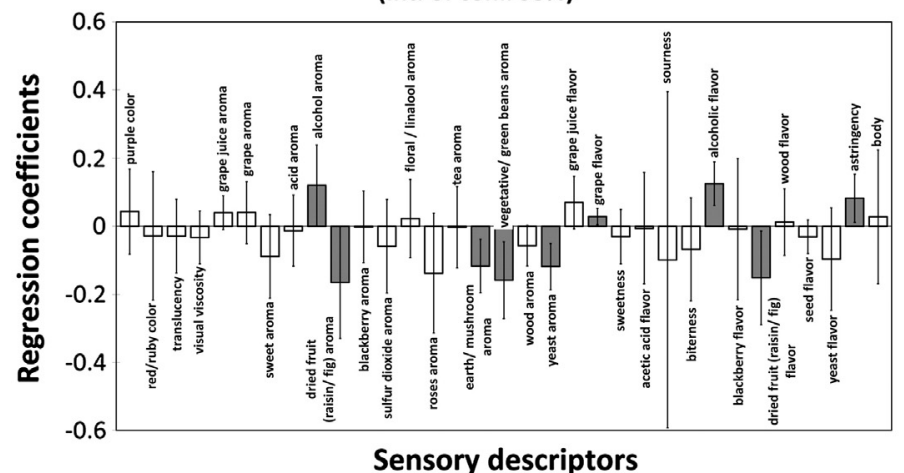

C Overall acceptability of the significant consumers of the segment $1(n=28)$ (Int. of conf. 95\%)

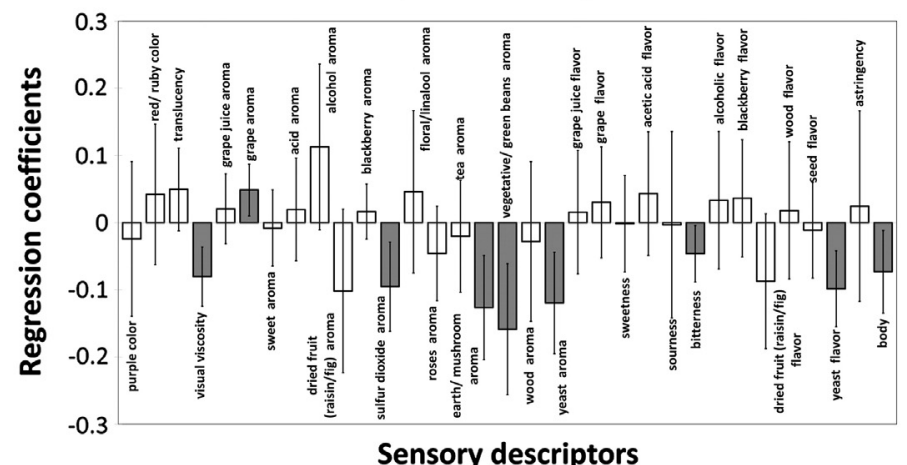

B

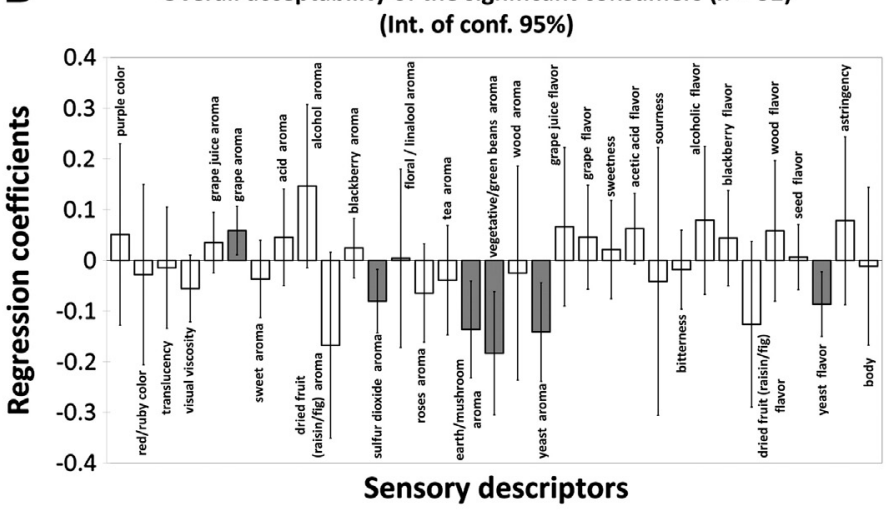

D Overall acceptability of the significant consumers of the segment 2 ( $n=19)$ (Int. of conf. 95\%)

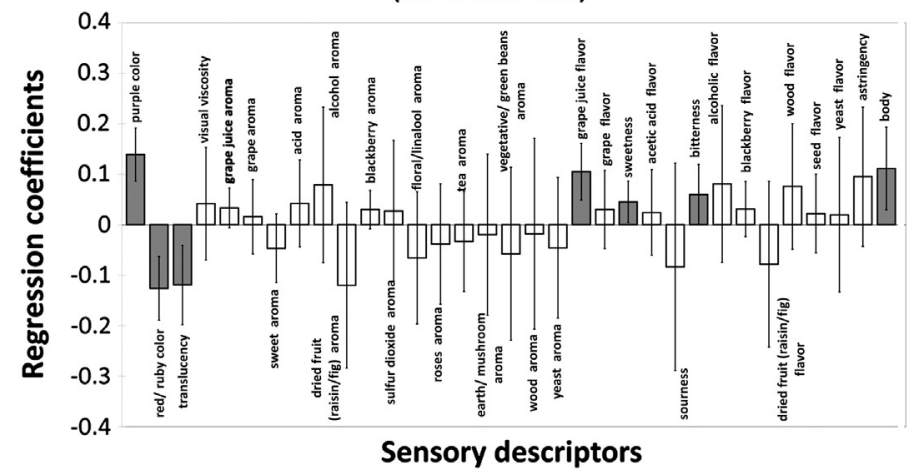

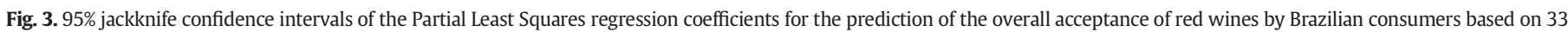

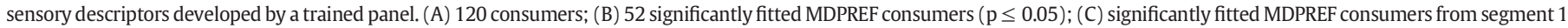

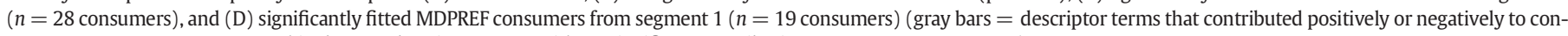
sumer acceptance at $\mathrm{p} \leq 0.05$; white bars $=$ descriptor terms with no significant contribution to consumer acceptance).

consumers of segment 2 (Fig. 3D). The consumers from clusters 3 and 5 (Fig. 4C and E) also appreciated the sweetness and the grape juice notes present in some wines, in addition to their blackberry aroma/ flavor ( $\mathrm{p} \leq 0.05$ ). Additionally the consumers from cluster 4 (Fig. 4D) appreciated the presence of note of alcohol aroma ( $p \leq 0.05$ ). These results clearly indicated that the sweetness and fruity notes associated with the aroma and flavor of grape, grape juice and blackberry were greatly appreciated by the majority of the consumers who participated in the sensory test and can be considered as preference drivers. Similar results were reported by Castilhos et al. (2012), who evaluated wines elaborated with Ives (100\%) and Isabella (100\%) varieties.

On the other hand, the descriptors placed in the lower part of Figs. 3 and 4 , whose confidence intervals do not include the value zero for the regression coefficient, represent sensory notes that contributed significantly ( $p \leq 0.05$ ) to decreasing acceptance amongst the consumers (Cadena et al., 2013; Tenenhaus et al., 2005). This was the case for the notes of earthy/mushroom, yeast and vegetative/green beans aromas in the PLS of the 120 consumers (Fig. 3A), in the PLS of the 52 consumers significantly ( $p \leq 0.05$ ) fitted in MDPREF (Fig. 3B) and in the PLS of the consumers of segment 1 (Fig. 3C), and in general for the 29 consumers located in cluster 1 (Fig. 4A), the 45 consumers of cluster 2 (Fig. 4B) and the 15 consumers of cluster 4 (Fig. 4D). Of all the wines tested, Barbera and Máximo wines presented the highest intensity $(\mathrm{p} \leq 0.05)$ of earthy/mushroom and yeast aromas, while Barbera and Máximo I showed the highest $(\mathrm{p} \leq 0.05)$ vegetative/green beans aroma (Table 4), explaining the low acceptance of these wines amongst the majority of consumers (Tables 2 and 3). For the 19 significantly fitted MDPREF consumers allocated in segment 2, Fig. 3D shows that the above mentioned notes did not impact their judgments positively or negatively ( $p \leq 0.05$ ). Similarly, these aroma notes did not influence the overall acceptability of the wines amongst the 15 consumers located in cluster 3 (Fig. 4C). The results of the PLS analysis shown in Fig. 3 also indicated that the aroma of sulfur dioxide contributed significantly $(\mathrm{p} \leq 0.05)$ to reducing acceptance of the wines amongst the 52 consumers significantly ( $\mathrm{p} \leq 0.05$ ) fitted in the MDPREF (Fig. 3B) and amongst the 28 significantly fitted MDPREF consumers of segment 1 (Fig. 3C). These results partially explain the low scores for acceptance awarded to the Maximo I and II wines by the 52 significant consumers ( $\mathrm{p} \leq 0.05$ ) and by the 28 individuals in segment 1 (Table 2 ). As can be seen in Table 4, Maximo I and II wines presented the greatest intensities of sulfur dioxide aroma, differing significantly $(\mathrm{p} \leq 0.05)$ from all the other wines except the Barbera wine.

In general, the aroma and flavor notes of dried fruit (raisin and fig), also contributed significantly ( $\mathrm{p} \leq 0.05$ ) to reducing acceptance of the wines amongst the consumers (Figs. $3 \mathrm{~A}$ and $4 \mathrm{E}$ ). In turn, the woody aroma and bitterness of the wines also contributed significantly ( $\mathrm{p}$ $\leq 0.05$ ) to reducing their acceptance amongst the 28 consumers of segment 1 of the MDPREF (Fig. 3C), and the 45 consumers located in cluster 2 (Fig. 4B). The acid aroma and the seed and woody flavors contributed to significantly ( $\mathrm{p} \leq 0.05$ ) reducing the acceptance of red wines amongst the 15 consumers of cluster 5 (Fig. 4E).

Figs. 3D and $4 \mathrm{C}$ suggests that the 19 consumers significantly ( $\mathrm{p}$ $\leq 0.05$ ) fitted in segment 2 of the MDPREF and the 15 consumers located in cluster 3 differed from the remaining consumers notably for their preference for wines showing purple color, visual viscosity, bitterness and body; and for disliking wines showing red/ruby color, translucency and sourness. This partly explains their preference for the wine elaborated with Máximo grapes (Máximo I), which stood out from the other wines for showing the highest intensity $(\mathrm{p} \leq 0.05)$ of purple color and lower translucency and red/ruby color (Table 4 ). 
A Overall acceptability of the significant consumer of the cluster $1(n=29)$ (Int. of conf. 95\%)

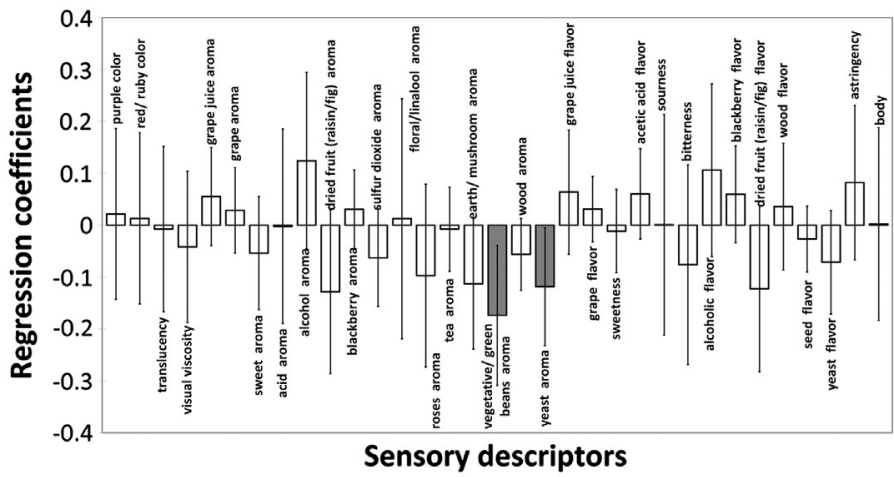

C Overall acceptability of the significant consumer of the cluster $3(n=15)$
(Int. of conf. 95\%)

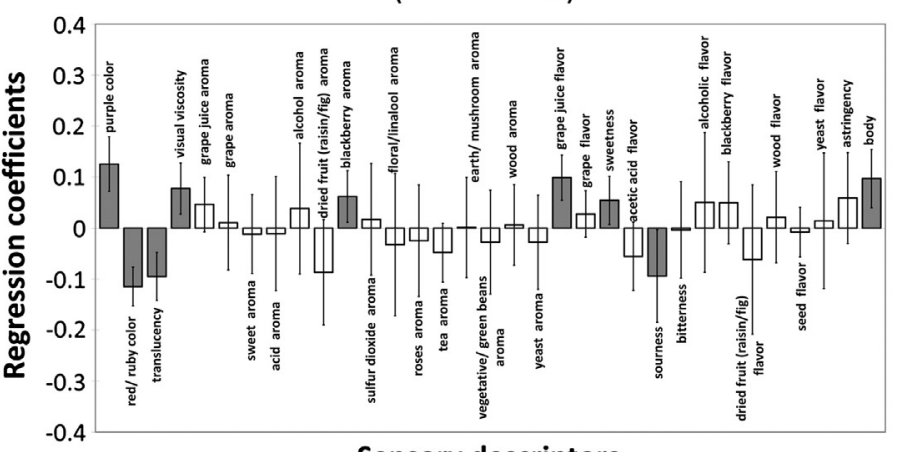

Sensory descriptors
B Overall acceptability of the significant consumer of the cluster $2(n=45)$ (Int. of conf. 95\%)

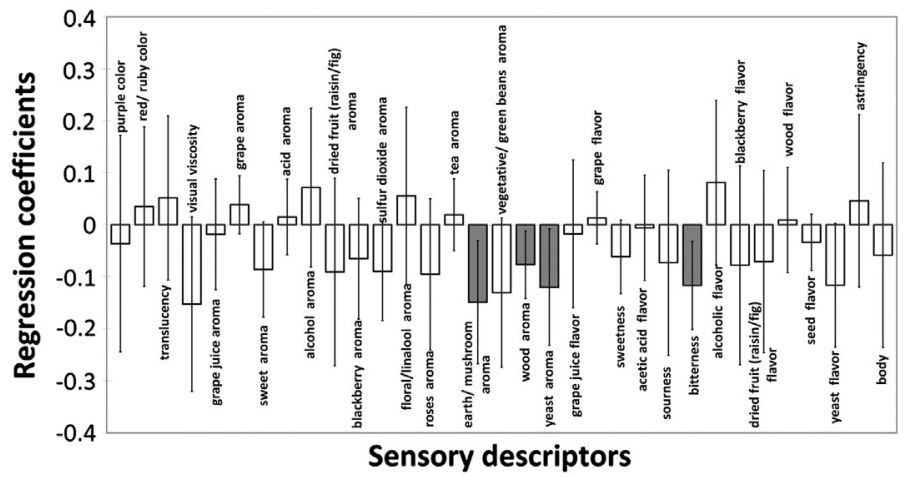

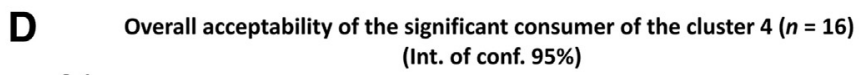

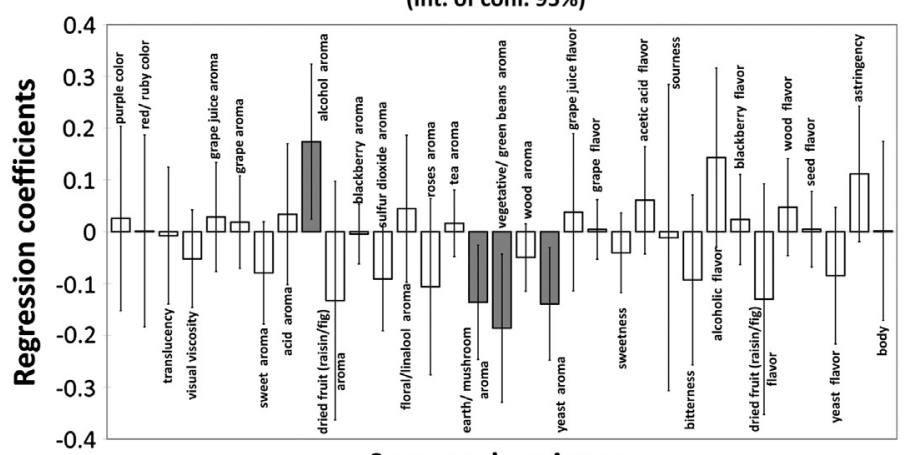

E Overall acceptability of the significant consumer of the cluster $5(n=15)$ (Int. of conf. 95\%)

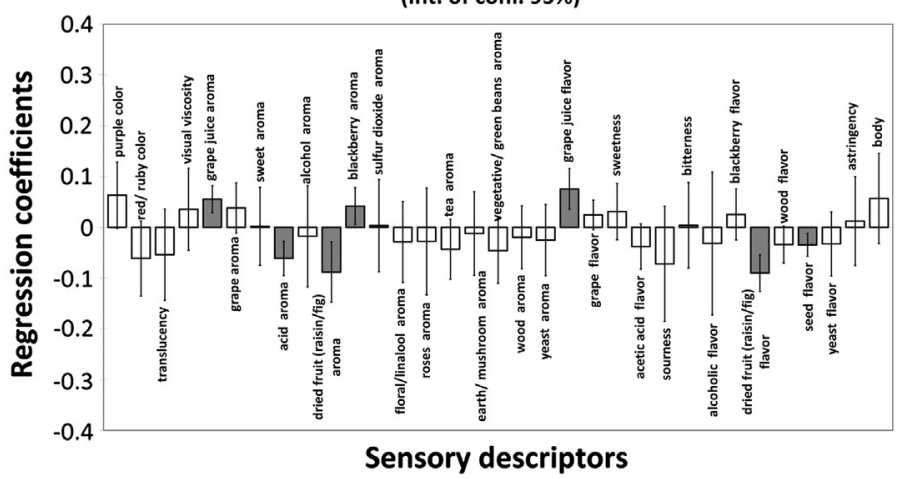

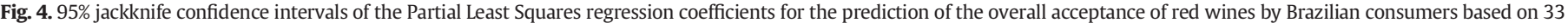

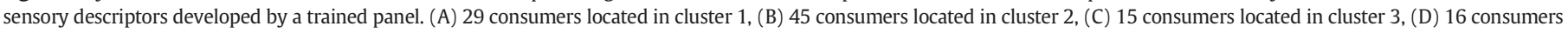

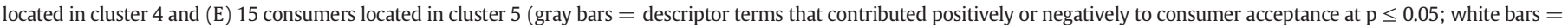
descriptor terms with no significant contribution to consumer acceptance).

In general, a comparison of Figs. 3 and 4 suggests that the consumers of segment 1 (Fig. 3C) show similarity with the consumers allocated in clusters 1 (Fig. 4A), 2 (Fig. 4B) and 4 (Fig. 4D) with regard to the sensory notes that contributed negatively to acceptance of the wines, while consumers from segment 2 of the MDPREF (Fig. 3D) and those located in cluster 3 (Fig. 4C) shared practically the same preference drivers.

\section{Chemical profile}

Table 5 shows the values obtained for the physicochemical parameters evaluated in the ten wines. The maximum value found for the $\mathrm{pH}$ was 3.82 (Maximo I) and the lowest value was 3.20 (Ives I). Wines with $\mathrm{pH}$ values above 3.9 have been shown to be susceptible to oxidation, to the loss of fresh aromas and to the loss of color, since the color of anthocyanins is altered with increasing $\mathrm{pH}$ of the wine, becoming bluish (Singleton, 1987). In the present study, the Máximo I wine, with a higher $\mathrm{pH}$ value, was that showing the greatest intensity of purple color, differing significantly from all the others, including the Máximo II wine, elaborated with the same grape variety. So, the purple color appreciated by the 19 consumers significantly ( $\mathrm{p} \leq 0.05$ ) fitted in segment 2 of the MDPREF (Fig. 3D) and by the 15 consumers located in cluster 3 (Fig. 4C), was possibly not a characteristic of the Máximo variety, but probably an effect of the wine $\mathrm{pH}$.

The Máximo I wine also stood out for its total solids content (Table 5), differing significantly from the others ( $p \leq 0.05$ ). According to Zoecklein, Fugelsang, Gump, and Nury (1999), the total solids content of wines is directly proportional to the perception of "body" in the wine, and is generally between 20 and $30 \mathrm{~g} \cdot \mathrm{L}^{-1}$ for red wines (Ough \& 


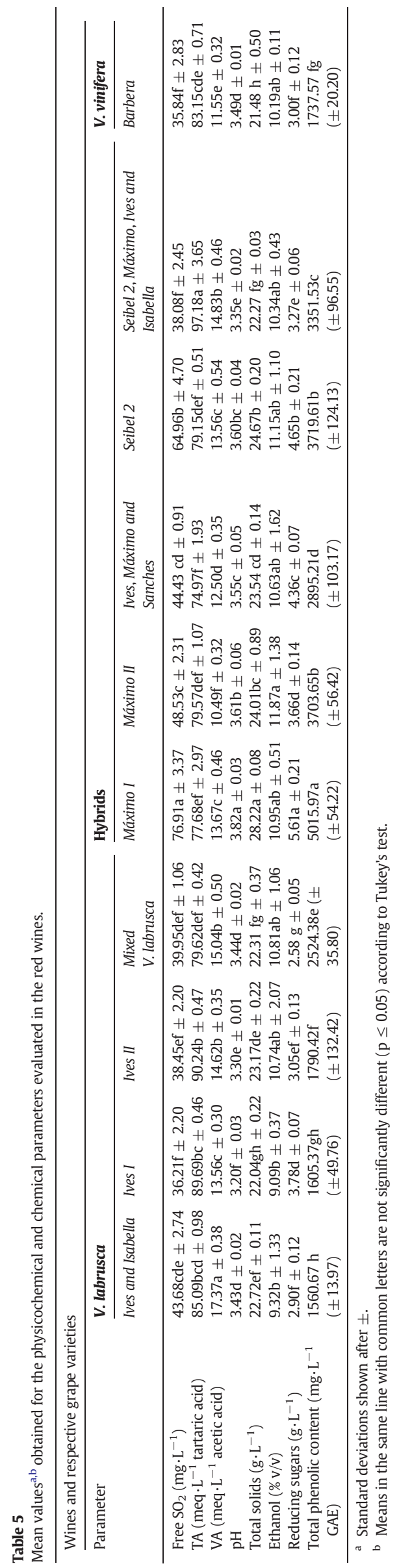

Amerine, 1988). In the current study, significant positive correlations were found between the total solids content and the sensory descriptor of body ( $\mathrm{r}=0.719, \mathrm{p}=0.02$ ) confirming results reported by Zoecklein et al. (1999). Correlation with the visual viscosity of the wines was also obtained $(\mathrm{r}=0.670, \mathrm{p}=0.03)$.

The reducing sugar content of the wines evaluated varied between $2.58 \mathrm{~g} \cdot \mathrm{L}^{-1}$ (wine produced with mixed non-revealed $V$. labrusca varieties), and $5.61 \mathrm{~g} \cdot \mathrm{L}^{-1}$ (Máximo I), as shown in Table 5. As in other beverages, in wine, in addition to conferring a sweet taste, the sugars also suppress the beverage sourness (Noordeloos \& Nagel, 1972) and accentuate the sensation of body in the mouth (Ishikawa \& Noble, 1995). In the present study there was a significant positive correlation $(\mathrm{r}=$ $0.829, \mathrm{p}=0.01$ ) between the reducing sugar content and the descriptor "body". However, no correlation was observed between the sugar content and the intensities of sweetness $(\mathrm{p}=0.70)$ and sourness $(\mathrm{p}=$ $0.92)$.

The total polyphenol contents of the wines analyzed varied between $1560.67 \mathrm{mg} \cdot \mathrm{L}^{-1}$ (Ives and Isabella), and $5015.67 \mathrm{mg} \cdot \mathrm{L}^{-1}$ (Máximo I), as shown in Table 5. According to Ough and Amerine (1988), the mean total phenolic content of red wines varies between 1900 and $38000 \mathrm{mg} \cdot \mathrm{L}^{-1}$. It is very clear in Table 5 that all the four wines containing the hybrid grape Maximo and the wine produced with Seibel 2 showed the highest total phenolic contents as compared with the wines that did not contain these grape varieties. The presence of stems and seeds in the must during maceration is amongst the factors that contribute to an increase in the levels of phenolic compounds in red wines (Sacchi, Bisson, \& Adams, 2005), but since the wines were produced in different wineries, it is more likely that the variety Máximo generates wines with high phenolic contents. As expected, significant positive correlations were found between the total phenolic compound content and bitterness $(r=0.654, p=0.04)$, "seed" flavor $(r=0.775$, $\mathrm{p}=0.01)$, body $(\mathrm{r}=0.625, \mathrm{p}=0.05)$ and astringency $(\mathrm{r}=0.958, \mathrm{p}$ $<0.01)$. These results are similar to those found by Noble and Shannon (1987) and Lee, Lee, Kim, Kim, and Koh (2006), who also observed a high positive correlation $(p<0.01)$ between the astringency perceived in red wines and the total phenolic compound content.

The levels of volatile acidity were above $8 \mathrm{meq} \cdot \mathrm{L}^{-1}$ (corresponding to $0.48 \mathrm{~g} \cdot \mathrm{L}^{-1}$ ) in all the wines evaluated (Table 5), values which suggest the occurrence of microbiological alterations in the beverages (Ough \& Amerine, 1988). High levels of volatile acidity alter the sensory quality of wines, since the perception of fruity aromas and flavors decreases as the volatile acidity increases (Zamora \& Guirao, 2002). In fact, Biasoto et al. (2010) reported a suppression effect ( $\mathrm{r}=-0.64, \mathrm{p}=$ 0.05 ) between the content of propionic acid, one of the acids making up the volatile acid fraction in wine, and the perception of fruity flavor notes in red wines, such as blackberry. However, in the current study, the volatile acidity did not negatively impact the acceptance of the wines amongst the consumers ( $\mathrm{p} \leq 0.05$ ).

The alcohol content of the wines varied from $9.09 \% \mathrm{v} / \mathrm{v}$ (Ives I) to $11.87 \% \mathrm{v} / \mathrm{v}$ (Máximo II). The ethyl alcohol content has a strong influence on the sensory characteristics (King, Dunn, \& Heymann, 2013), and can increase the mouth perceptions of body (Gawel, Sluyter, \& Waters, 2007) and bitterness (Noble, 1998; Sokolowsky \& Fischer, 2012), alter the perception of sweetness (Zamora, Goldner, \& Galmarini, 2006), suppress the sourness (Williams, 1972) and reduce astringency (Fontoin, Saucier, Teissedre, \& Glories, 2008). In the present study, significant correlations between the alcohol content and the sensory descriptors were only found for bitterness $(\mathrm{r}=0.713, \mathrm{p}=0.02)$ and for alcoholic flavor $(\mathrm{r}=0.699, \mathrm{p}=0.02)$.

\section{Extended Internal Preference map}

Fig. 5 presents the Extended Internal Preference Mapping - EPM generated in the current study to relate the data from the descriptive and chemical analyses with the consumers' overall acceptability (Fig. 5). For a better visualization of the EPM results, each wine is 
A

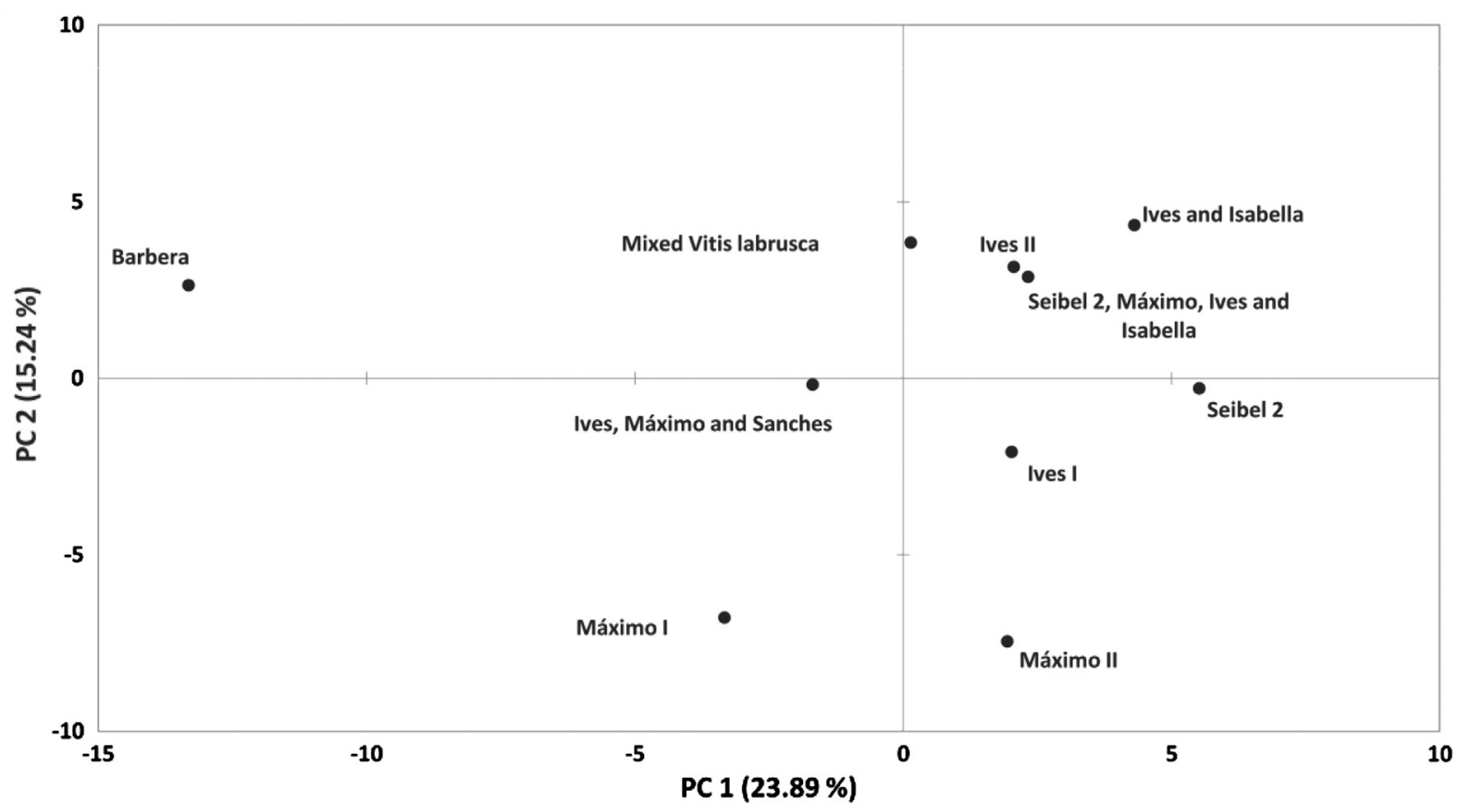

B

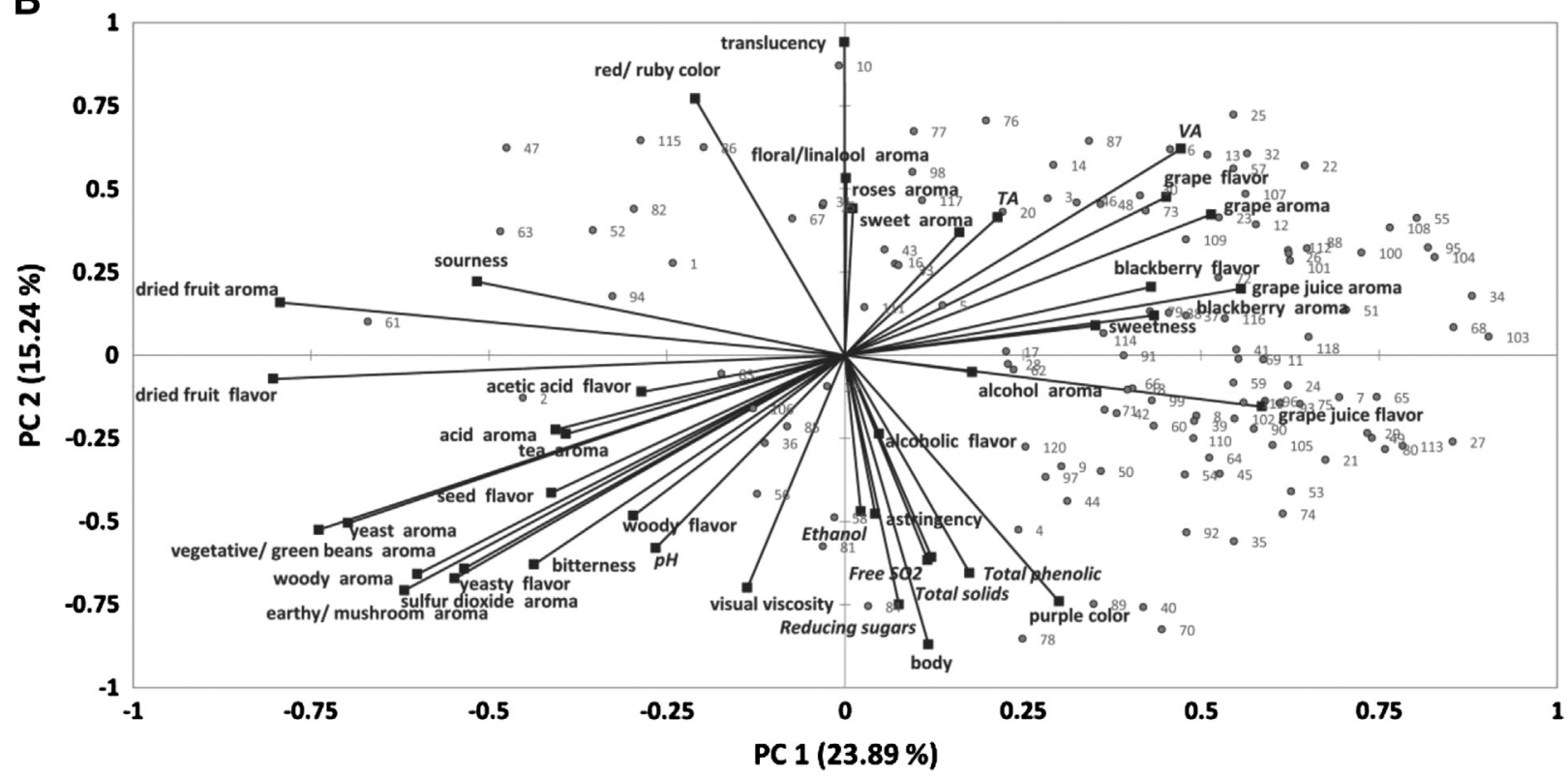

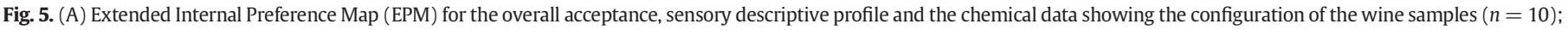

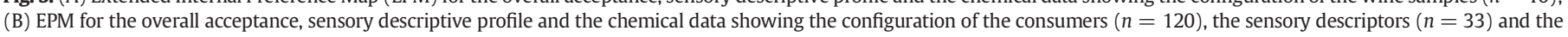
chemical parameters $(n=8)$.

represented in Fig. 5A, and the 120 consumers that evaluated the samples are shown in Fig. 5B, indicated by the numbers from 1 to 120. In turn, each sensory descriptor and chemical parameter evaluated in the wines is represented in Fig. $5 \mathrm{~B}$ as a vector. For the interpretation of the EPM, Fig. 5A and B should be superimposed.

In Fig. 5, each subject is close to the sample of his/her preference and also to the sensory descriptors and chemical parameters that positively influenced his/her preference regarding the wines. As can be seen, the vast majority of the consumers represented in Fig. 5A are close to the sensory descriptors specified as aroma and flavor of grape, grape juice, blackberry and sweet, and the aroma note described as alcohol. These results endorse those obtained by the PLS analysis of the data (Figs. 3 and 4), and confirm that the above mentioned descriptors are preference drivers for red wines amongst the consumers who participated in the test. It can also be noted in Fig. 5 that most of the consumers are close to the wines elaborated with the grape Seibel 2 and that made with a mixture of Ives and Isabella grapes; confirming the results obtained by the MDPREF analysis (Fig. 1) which indicated that these samples were the most preferred amongst the subjects who participated in the test.

It can be seen in Fig. 5 that a large number of consumers are close to the vector representing the volatile acidity (VA) of the wines. This can be attributed to the fact that one of the favorite wines, that produced from the Isabella and Ives grapes, stood out from the others due to its higher volatile acidity (Table 5). Thus, in the range of variation observed in the current study (Table 5) for volatile acidity, it did not negatively 
impact acceptance of the wines amongst the consumers, as stated in the literature (Ough \& Amerine, 1988; Zamora \& Guirao, 2002).

Finally, in Fig. 5, the sensory descriptors that are opposite the region where the majority of consumers are located, such as the sourness and the aroma and flavor of dried fruit, indicate attributes that negatively influenced acceptance of the wines amongst the consumers who participated in the test. As shown in Figs. 3 and 4, these same results were obtained when the data was explored by the PLS analysis. In fact, the Barbera wine, which presented the highest intensities of these attributes (Table 4), was the least preferred wine amongst most consumers.

\section{Conclusions}

In general wines containing the $V$. labrusca grape Ives showed more intense aroma/flavor notes described as sweet, grape, grape juice, blackberry and roses. In turn, wines produced with the hybrid grapes Máximo were characterized by a greater intensity of earthy/mushroom, vegetative/green beans, woody and yeast sensory notes.

The aroma and flavor notes described as grape, grape juice, blackberry and sweet, and the aroma note described as alcohol can be considered as preference drivers for red wines amongst the consumers who participated in the test. On the other hand, the majority of the consumers did not like the sensory notes described as earthy/mushroom, yeast and vegetative/green beans found in some wines, notably those elaborated with the $V$. vinifera Barbera and Máximo grapes. Overall, consumers also disliked the aroma/flavor notes described as dried fruit, such as raisin and fig.

Together with the wine produced with Seibel 2 grapes, all the wines containing the hybrid grape Maximo showed the highest total phenolic contents as compared with the wines that did not contain these grapes, in spite of the fact the beverages were produced in different wineries. Significant positive correlations were found between the total phenolic compound content and "seed" flavor, astringency, bitterness and body.

The wines elaborated exclusively with the hybrid grape Seibel 2 or containing the $V$. labrusca varieties Ives and Isabella were preferred by the majority of the consumers. Thus, these represent promising grapes for the production of quality wines in Brazilian regions where the environmental conditions are not good for the growing of $V$. vinifera grapes. The wines elaborated solely with the hybrid grape Máximo were appreciated by a minor segment of consumers. Therefore, the use of this grape in Brazilian wines deserves additional studies.

Overall, the cluster and MDPREF analyses showed a similar pattern of consumer segmentation, although the cluster analysis allowed for a greater segmentation of the subjects.

\section{Acknowledgments}

The authors are grateful to the wineries for providing the wines and to the National Council for Scientific and Technological Development (CNPq, Brazil) (number process 131017/2006-3) for its financial support.

\section{References}

Amerine, M.A., \& Singleton, V. L. (1984). Wine an introduction (3rd ed.). Berkeley, CA: University of California Press.

AOAC - Association of official analytical chemists (2005). Gaithersburg, USA: AOAC International The Scientific Association.

Biasoto, A.C. T., Catharino, R. R., Sanvido, G. B., Eberlin, M. N., \& Da Silva, M.A. A. P. (2010). Flavor characterization of red wines by descriptive analysis and ESI mass spectrometry. Food Quality and Preference, 21, 755-762.

Cadena, R. S., Cruz, A. G., Rolim Neto, R., Castro, W. F., Faria, J. A. F., \& Bolini, H. M.A. (2013). Sensory profile and physicochemical characteristics of mango nectar sweetened with high intensity of sweeteners throughout storage time. Food Research International, 54, 1670-1679.

Camargo, U. A., \& Ritschel, P. (2008). New table and wine grape cultivars: World scenario with emphasis on brazil. Acta Horticulturae, 785, 89-96.

Castilhos, M. B.M., Silva, A.C. C., \& Bianchi, V. L. D. (2012). Effect of grape pre-drying and static pomace contact on physicochemical properties and sensory acceptance of
Brazilian (Bordô and Isabel) red wines. European Food Research and Technology, 235, 345-354.

Cochran, W. G., \& Cox, G. M. (1957). Experimental designs (2nd ed.). New York: John Wiley and Sons, Inc.

Fontoin, H., Saucier, C., Teissedre, P. L., \& Glories, Y. (2008). Effect of pH, ethanol and acidity on astringency and bitterness of grape seed tannin oligomers in model wine solution. Food Quality and Preference, 19, 286-291.

Gawel, R., Sluyter, S. V., \& Waters, E. J. (2007). The effects of ethanol and glycerol on the body and others sensory characteristics of Riesling wines. Australian Journal of Grape and Wine Research, 13, 38-45.

Hamada, E., Ghini, R., Rossi, P., Pedro Júnior, M. J., \& Fernades, J. L. (2008). Climatic risk of grape downy mildew (Plasmopara viticola) for the state of São Paulo, Brazil. Scientia Agricola, 65, 60-64.

IBGE. Banco de dados agregados (2013). Pesquisa industrial anual produto. http://www. sidra.ibge.gov.br/bda/tabela/protabl.asp?c $=3337 \& \mathrm{z}=\mathrm{t} \& \mathrm{o}=22 \mathrm{i}=\mathrm{P}$ (access in January 10)

Ishikawa, T., \& Noble, A.C. (1995). Temporal perception of astringency and sweetness in red wine. Food Quality and Preference, 6, 27-33.

Jackson, R. S. (2008). Wine science: Principles, practice and perception (3rd ed.). San Diego, CA, USA: Elsevier Inc.

Jackson, R. S. (2009). Wine tasting: A professional handbook (2nd ed.). San Diego, CA, USA Elsevier Inc.

King, E. S., Dunn, R. L., \& Heymann, H. (2013). The influence of alcohol on the sensory perception of red wines. Food Quality and Preference, 28, 235-243.

Lago-Vanzela, E. S., Rebello, L. P. G., Ramos, A.M., Stringheta, P. C., Da-Silva, R., GárciaRomero, E., et al. (2013). Chromatic characteristics and color-related phenolic composition of Brazilian young red wines made from the hybrid cultivar BRS-Violeta ("BRS-Rúbea" × "IAC1398-21"). Food Research International, 54, 33-43.

Lee, S. -J., Lee, J. -E., Kim, H. -W., Kim, S. -S., \& Koh, K. -H. (2006). Development of Korean red wines using Vitis labrusca varieties: Instrumental and sensory characterization. Food Chemistry, 94, 385-393.

MacFIE, H. J. H., \& Thomson, D.M. H. (1988). Preference mapping and multidimensional scaling. In J. R. Piggott (Ed.), Sensory Analysis of Foods (pp. 380-409). London: Elsevier Applied Science.

Moskowitz, H. R. (1983). Product testing and sensory evaluation of foods: Marketing and R E $D$ approaches. Westport: Food \& Nutrition Press.

Noble, A.C. (1998). Why do wine taste bitter and fell astringent? Chemistry of wine flavor ACS Symposium series 174 (pp. 156-165). Portland, OR: Oxford University Press.

Noble, A.C., Arnold, J., Buechsenstein, A., Leach, E. J., Schmidt, J. O., \& Stekrn, P.M. (1987). Modification of a standardized system of wine aroma terminology. American Journal of Enology and Viticulture, 38, 143-146.

Noble, A.C., \& Shannon, M. (1987). Profiling Zinfandel wines by sensory and chemica analyses. American Journal of Enology and Viticulture, 38, 1-5.

Noordeloos, S., \& Nagel, C. W. (1972). Effect of sugar on acid perception in wine. American Journal of Enology and Viticulture, 23, 139-143.

Ough, C. S., \& Amerine, M.A. (1988). Methods for analysis of musts and wines (2nd ed.). New York: John Wiley and Sons, Inc.

Reynolds, A. G., Lowrey, W. D., \& De Savigny, C. (2005). Influence of irrigation and fertigation on fruit composition, vine performance, and water relations of Concord and Niagara grapevines. American Journal of Enology and Viticulture, 56, 110-128.

Rossi, J. A., \& Singleton, V. L. (1965). Colorimetry of total phenolics with phosphomolybdic phosphotungstic acid reagents. American Journal of Enology and Viticulture, 16 144-158.

Sacchi, K. L., Bisson, L. F., \& Adams, D. O. (2005). A review of the effect of winemaking techniques on phenolic extraction in red wines. American Journal of Enology and Viticulture, 53, 197-206.

Singleton, V. L. (1987). Oxygen with phenols and related reactions in must, wines and model systems, observations and practical implications. American Journal of Enology and Viticulture, 38, 69-77.

Sokolowsky, M., \& Fischer, U. (2012). Evaluation of bitterness in white wine applying descriptive analysis, time-intensity analysis, and temporal dominance of sensations analysis. Analytica Chimica Acta, 732, 46-52.

Stone, H. S., Sidel, J. L., Oliver, S., Woosley, A., \& Singleton, R. C. (1974). Sensory evaluation by Quantitative descriptive analysis. Food Technology, 28, 24-34.

Tenenhaus, M., Pagès, J., Ambroisine, L., \& Guinot, C. (2005). PLS methodology to study relationships between hedonic judgements and product characteristics. Food Quality and Preference, 16, 315-325.

Villanueva, N., \& Da Silva, M.A. A. P. (2009). Comparative performance of the nine-point hedonic, hybrid and self-adjusting scales in the generation of internal preference maps. Food Quality and Preference, 20, 1-12.

Wakeling, I. N., \& MacFIE, H. J. H. (1995). Designing consumer trials balanced for first and higher orders of carry-over effect when only a subset of k samples from t may be tested. Food Quality and Preference, 6, 299-308.

Williams, A. A. (1972). Flavour effects of ethanol in alcoholic beverages. The Flavour Industry, 21, 601-611.

Zamora, M. C., Goldner, M. C., \& Galmarini, M. V. (2006). Sourness-sweetness interactions in different media: White wine, ethanol and water. Journal of Sensory Studies, 21 601-611.

Zamora, M. C., \& Guirao, M. (2002). Analysing the contribution of orally perceived attributes to the flavor of wine. Food Quality and Preference, 13, 275-283.

Zoecklein, B. W., Fugelsang, K. C., Gump, B. H., \& Nury, F. S. (1999). Wine analysis and production. Gaithersburg, Maryland: Aspen Publishers. 